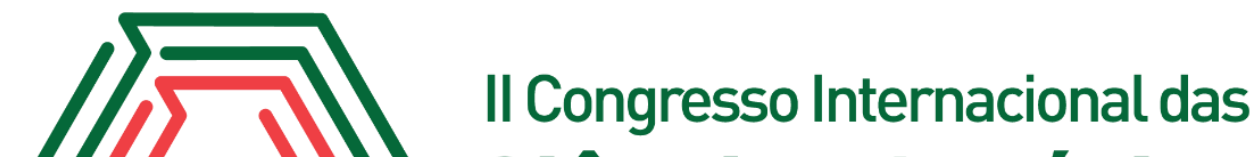 Ciências Agrárias COINTER - PDVAgro 2017
}

\section{CONTAGEM DE PSICROFILOS E MESÓFILOS EM CARNE BOVINA MARINADA COM DIFERENTES CONCENTRAÇÕES DE PRÓPOLIS}

\author{
Apresentação: Pôster
}

Uri Vanille Raiol da Silva ${ }^{1}$, Maria Raquel Lopes Silva ${ }^{1}$, Elaine Cristine Alves Soares ${ }^{1}$, Allison Ferreira de Lima ${ }^{2}$, Patrícia de Oliveira Lima ${ }^{3}$

\begin{abstract}
${ }^{1}$ Mestranda do programa de pós-graduação em produção animal - UFERSA, Mossoró- RN, Brasil, uri_raiol@hotmail.com,raquellopes-16@ hotmail.com, elainesoares01@yahoo.com.br; ${ }^{2}$ Mestrando do programa de pós- graduação em ciência animal - UFERSA, Mossoró- RN, Brasil, henresito @ hotmail.com; ${ }^{3}$ Docente associado I (CCA/DCAN) Universidade Federal Rural do Semi-Árido-UFERSA, Mossoró-RN, Brasil
\end{abstract}

\section{Introdução}

Atualmente os consumidores estão se tornando mais exigentes quanto à qualidade dos alimentos, e eles esperam que isso seja mantido no período entre a compra e o consumo final. Essas expectativas são consequência não só da demanda por produtos seguros, mas também da necessidade de minimizar as alterações indesejadas nas suas qualidades. Dessa forma, satisfazer os consumidores é um desafio que pode resultar em receitas financeiras para as indústrias de alimentos (OLIVEIRA et al., 2016).

O aumento da demanda de carne faz com que as indústrias do mundo inteiro invistam, cada vez mais, em tecnologias capazes de agregar valor aos produtos. A industrialização é a principal alternativa para o escoamento da matéria prima, além de proporcionar um aumento na vida útil dos produtos (TROY; KERRY, 2010).

Sendo assim, a presente pesquisa objetivou avaliar o efeito das diferentes concentrações de extrato aquoso da propólis sobre as microbiológicas da carne bovina

\section{Fundamentação Teórica}

O uso de conservantes naturais para aumentar a vida útil da carne, assim como dos produtos oriundos dela, é uma tecnologia promissora, uma vez que muitas substancias possuem propriedades antioxidante e antimicrobiana (FERNÁNDEZ-GINÉS et al., 2005). 
Embora ainda pouco estudada, a utilização de extratos naturais atuando como antimicrobianos tem sido uma boa alternativa na substituição de conservantes sintéticos para aqueles que buscam uma alimentação mais saudável (ZACARÃO, 2013).

Nagai et al. (2006) relatam que a própolis apresenta um efeito inibitório elevado contra o crescimento microbiano durante a conservação da carne e músculo. Lee et al. (2003) relatam que o extrato de própolis apresenta ação antimicrobiana contra o Staphylococcus aureus.

\section{Metodologia}

A presente pesquisa é caracterizada quanto a sua natureza como quantitativa do tipo experimental e foi realizado no Laboratório de Análises Instrumentais e Sensoriais (LANIS) e Laboratório de Inspeção de Produtos de Origem Animal (LIPOA).

A carne utilizada foi coxão duro (biceps femoris), e foi fracionada em bifes de aproximadamente $200 \mathrm{~g}$ cada (no sentido perpendicular e longitudinalmente as fibras), totalizando $1.200 \mathrm{Kg}$ por tramento. Quanto ao extrato aquoso da própolis (EAP), essa foi gentilmente doada por apicultores do Rio Grande do Norte.

O marinado continha a mistura de água destilada e EAP em diferentes concentrações, dando origem aos tratamentos foco do estudo. Sendo eles: o controle - T1 (apenas água destilada), T2 (0,2\% de EAP/ $100 \mathrm{~g}$ de água destilada) e T3 (0,5\% de EAP/ 100g de água destilada). Após o preparo das soluções, os bifes fracionados em igual valor foram deixados imersos por 15 minutos, e em seguida acondicionados em sacos plásticos (esterilizados) com zip loock, identificados de acordo com cada tratamento.

As amostras de carne foram submetidas às técnicas para contagem total de bactérias psicrotróficas, bactérias aeróbias mesófilas e Salmonella sp. utilizando a metodologia oficial (BRASIL, 2003). Com base em uma adaptação a metodologia descrita por Câmpelo (2016), foram realizadas as análises microbiológicas das amostras das carnes acondicionadas em nos seguintes tempos de armazenamento: $0,3,6,9,12$ e 15 dias, sob refrigeração a $4^{\circ} \mathrm{C} \pm 1^{\circ}$, simulando assim, a vida de prateleira.

No que se refere à análise estatística, os dados foram submetidos à análise de variância e teste de comparação de médias. Os efeitos dos diferentes tratamentos sobre cada variável foi comparado por meio do teste de Tukey, ao nível de 5\% de probabilidade. Tais procedimentos mencionados foram conduzidos no PROC GLM do SAS (Statistical Analysis System, versão 9.2). 


\section{Resultados e Discussões}

Para análise microbiológica para contagem de mesófilos aeróbios houve diferença estatística quanto ao tratamento nos dias 3, 9 e 12, onde o tratamento 2 com $0,2 \%$ de extrato de própolis foi o que apresentou crescimento moderado com o avançar dos dias de armazenamento para mesófilos aeróbios, já o tratamento 3 com $0,5 \%$ de EAP mostrou uma diminuição dos valores a partir do dia 6 de armazenamento. Os resultados estão expressos na Tabela 1.

Tabela 1: Contagem de microrganismos mesófilos aeróbios durante armazenamento de carne refrigerada, acondicionada com extrato de própolis.

\begin{tabular}{|c|c|c|c|c|c|}
\hline \multirow{2}{*}{$\begin{array}{l}\text { Dias de } \\
\text { armazenamento }\end{array}$} & \multirow{2}{*}{ Microrganismos } & \multicolumn{3}{|c|}{ Concentrações de extrato de própolis } & \multirow{2}{*}{$\mathrm{CV}(\%)$} \\
\hline & & 0 & 0,2 & 0,5 & \\
\hline 0 & \multirow{5}{*}{ MESÓFILOS } & $4,49 \mathrm{Ca}$ & $4,44 \mathrm{Ba}$ & $4,60 \mathrm{Ca}$ & \multirow{5}{*}{3,77} \\
\hline 3 & & $5,63 \mathrm{Bb}$ & $5,67 \mathrm{Ab}$ & 6,35 Aa & \\
\hline 6 & & 6,07 Aba & 5,88 Aa & $5,85 \mathrm{ABa}$ & \\
\hline 9 & & $6,29 \mathrm{Aa}$ & $5,98 \mathrm{Aa}$ & $5,12 \mathrm{Bb}$ & \\
\hline 12 & & $6,30 \mathrm{Aa}$ & $6,15 \mathrm{Aa}$ & $5,10 \mathrm{Bb}$ & \\
\hline
\end{tabular}

Letras maiúsculas distintas na coluna indicam diferença entre os tempos de armazenamento E letras minúsculas distintas na linha indicam diferença entre os tratamentos pelo teste Tukey $5 \%$.

Os resultados não corroboram com os achados na literatura, onde Kalogeropoulos et al. (2009) trabalhando com extrato de própolis etanólico da Grécia e do Chipre relataram que apresentaram espectro de inibição comparáveis ao da nisina, um antimicrobiano (bacteriocina) usado em alimentos produzido por Lactococcus lactis subsp. lactis e usado como conservador natural em queijos processados, leite, produtos enlatados, ovo líquido entre outros alimentos.

Tais resultados apresentados na tabela 1 sugerem que a carne bovina já apresentava microrganismos, pois trabalhos semelhantes como o de Alves et al. (2009), apresentaram resultados satisfatórios com a utilização de extrato de própolis na conservação de linguiças toscana, inibindo o crescimento microbiano.

Para contagem de psicrófilos houve diferença estatística quanto aos dias de armazenamento a partir do dia 6, mostrando diferenças entre os tratamentos. Os resultados estão expressos na Tabela 1. 
Tabela 2: Contagem de microrganismos psicrófilos durante armazenamento de carne refrigerada, acondicionada com extrato de própolis.

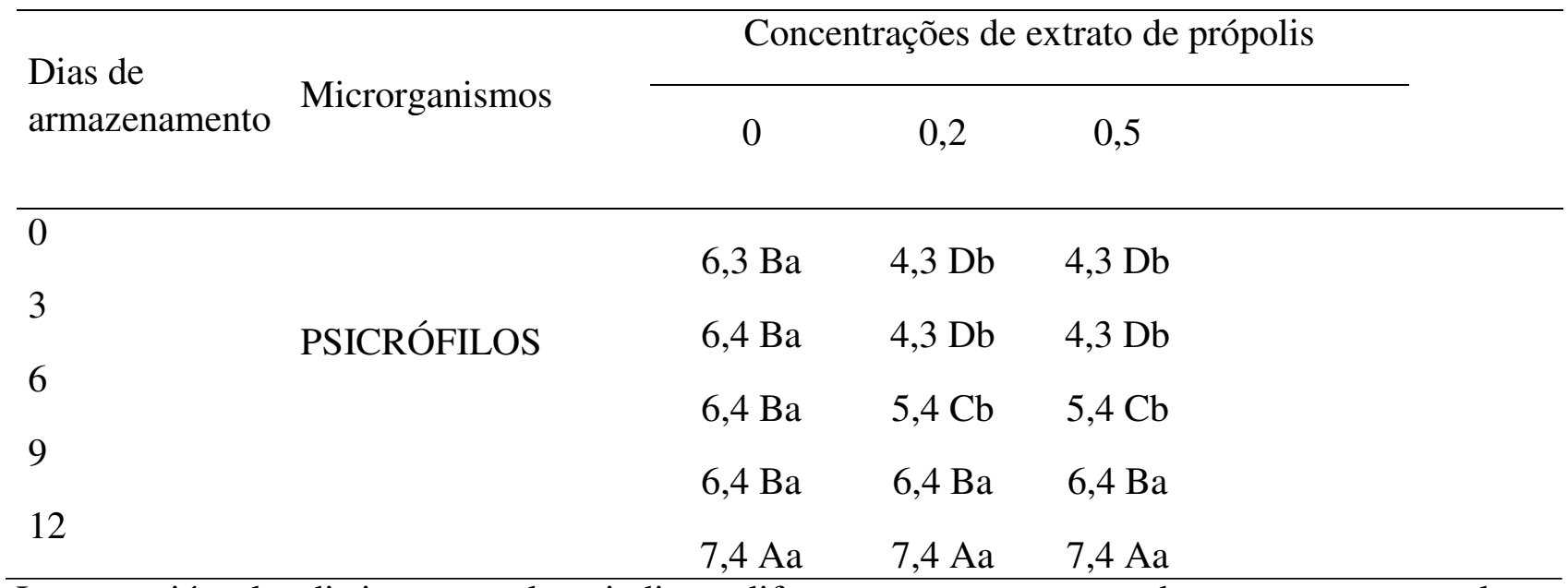

Letras maiúsculas distintas na coluna indicam diferença entre os tempos de armazenamento e letras minúsculas distintas na linha indicam diferença entre os tratamentos pelo teste Tukey $5 \%$.

O crescimento de psicrófilos observado a partir do dia 9 sugere uma redução na eficácia da própolis como agente bactericida. Os achados de Orsi et al. (2005) e Gutierrez Cortés (2012) corroboram com o presente resultado, onde sugerem que uma vez que a gordura da carne cobre os microrganismos e protege-os da própolis, a mesma perde sua eficácia, sendo sugerido concentrações mais altas para que sua eficácia não seja prejudicada.

\section{Conclusões}

Nenhuma concentração de extrato de própolis foi suficiente para impedir totalmente o crescimento dos microrganismos presentes na carne no decorrer dos dias de armazenamento, entretanto, a inserção do extrato aquoso de própolis na concentração de $0,5 \%$ contribuiu para a diminuição de mesófilos apresentando melhores resultados frente às outras concentrações utilizadas a partir do $6^{\circ}$ dia de avaliação.

\section{Referências}

ALVES, E. et al. ATIVIDADE ANTIOXIDANTE DE EXTRATOS DE PRÓPOLIS COMERCIALIZADOS EM SANTA MARIA-RS E APLICAÇÃO EM LINGÜIÇA TOSCANA REFRIGERADA. 2009.

CAMPÊLO, M. C. S. Uso de conservadores naturais na elaboração de carne de sol com teores reduzidos de cloreto de sódio. 2016. 70 f. Dissertação (Mestrado) - Curso de Pós- Graduação em Ciência Animal, Universidade Federal Rural do Semi-Árido, Mossoró, 2016.

FERNÁNDEZ-GINÉS, J. M. et al. Meat products as functional foods: a review. Journal of Food 
Science, v. 70, n. 2, p. 37-43, 2005.

GUTIERREZ CORTÉS, Carolina et al. Evaluación del efecto de propoleos como biopreservante en chorizo. 2012. Tese de Doutorado. Universidad Nacional de Colombia.

KALOGEROPOULOS, N. et al. Chemical composition, antioxidant activity and antimicrobial properties of propolis extracts from Greece and Cyprus. Food Chemistry, v.116, p.452-461, 2009.

LEE, L.; CHEN, Y.; CHOU, C. Antibacterial activity of propolis aganist Staphylococcus aureus. International Journal of Food Microbiology, Taipei, v. 102, n. 2, p. 213-220, July 2003.

NAGAI, T. et al. Characterization of honey from different floral sources. Its functional properties and effects of honey species on storage of meat. Food Chemistry, London, v. 97, n. 2, p. 256-262, July 2006.

OLIVEIRA, R. B. S. et al. Quality of beef burger with addition of wet okara along the storage. Ciência e Agrotecnologia, [s.1.], v. 40, n. 6, p.706-717, dez. 2016.

ORSI R. O. et al. Susceptibility profile of salmonella against the antibacterial activity of propolis produced in two regions of brazil. En: J. Venom. Anim. Toxins incl. Trop. Dis. 2005. Vol 11, 2, p. 110.

TROY, D.J.; KERRY, J.P. Consumer perception and the role of science in the meat industry, Meat Science. V.86, n.1, p. 214-226, 2010.

ZACARÃO, Paula Choseck. Estudo da propriedade antimicrobiana dos óleos essenciais de alho (allium sativum), pimenta do reino (piper nigrum) e pimenta rosa (schinus molle) para aplicação em cortes de frango temperados. 2013. 